\title{
P-0909 PREVALENCE OF NEUROPATHY IN PREDIABETES AND HEALTHY VOLUNTEERS BY QUANTITATIVE ASSESSMENT OF SUDOMOTOR FUNCTION
}

R. Gabriel ${ }^{1,2}$. JH. Calvet ${ }^{3}$, A. Vilier ${ }^{3}$, N. Boukichou ${ }^{2}$, J. Tuomilehto ${ }^{2,4}$ on behalf of ePREDICE Study Group.

${ }^{1}$ Instituto de Salud Carlos III, Escuela Nacional de Sanidad, Madrid, Spain.

${ }^{2}$ Evidem Consultores. ePREDICE Coordinating Centre, Madrid. Spain

3IMPETO MEDICAL. Paris, France

${ }^{4}$ Dasman Diabetes Institute. Kuwait City, Kuwait

\section{BACKGROUND}

Sudomotor function is used to evaluate the peripheral autonomic system. Several studies have shown sudomotor dysfunction in diabetes and prediabetes. Measurement of Electrochemical Skin Conductance (ESC) based on the electrochemical reaction between the chloride ions in sweat and stainless steel plate electrodes is a simple, non-invasive, and quick method allowing assessment of sweat gland function. Previous studies have reported that ESC measurement correlates well with other validated sudomotor standards. However, sweat function is influenced by factors as age, sex, race, BMI, and glycaemic status. Therefore a need remains to describe the performance of this technology in the prediabetic stage.

\section{AIM}

1) To compare the Electrochemical Skin Conductance (ESC) values and distribution measured by SUDOSCAN in adult with prediabetes and healthy volunteers.

2) To estimate the prevalence of Neuropathy and Cardiovascular Autonomic Neuropathy (CAN) among adult prediabetic subjects and healthy volunteers.

\section{RESULTS}

Table 1. Percentage of neuropathy and CAN defined by SUDOSCAN in the two populations

\begin{tabular}{lccc}
\hline & Prediabetics & $\begin{array}{c}\text { Healthy } \\
\text { volunteers }\end{array}$ & P value \\
\hline Neuropathy as defined by SUDOSCAN, $\mathbf{n}(\%)$ & & \multicolumn{3}{c}{$<0.0001$} \\
$\quad$ No neuropathy & $310(69)$ & $350(91)$ & \\
Neuropathy & $117(26)$ & $33(9)$ & \\
$\quad$ Severe neuropathy & $20(5)$ & $0(0)$ & \\
CAN risk score, $\mathbf{n}(\%)$ & & & $<0.0001$ \\
$<30$ & $200(44.7)$ & $382(99)$ & \\
$\geq 30$ & $203(55.3)$ & $1(1)$ & \\
\hline
\end{tabular}

$\mathrm{P}$ value for $\mathrm{X}^{2}$ test.

\section{METHOD}

Study population. 447 prediabetic individuals (59\% females), 45 74 years old, with IFG or IGT or IFG+IGT, recruited in the ongoing multicentre European Randomized Clinical Trial ePREDICE (Early Prevention of Diabetes Complications in People with Hyperglycaemia in Europe). 383 healthy volunteers (83\% females), 22-65 years old.

Measurements: SUDOSCAN test, HbA1c, OGTT-2h, BMl and waist circumference were measured at baseline.

Neuropathy is defined according to SUDOSCAN results: a) No neuropathy: hands ESC $\geq 60 \mu S$ and feet ESC $\geq 70 \mu S$; b) Neuropathy: hands ESC between $40-60 \mu S$ or feet ESC between 50-70 $\mu \mathrm{S}$; and c) Severe neuropathy: hand ESC $<40 \mu S$ or feet ESC $<50 \mu \mathrm{S}$. Cardiovascular Autonomic Neuropathy (CAN) was defined according to CAN risk score: $<30$ no risk of CAN, $\geq 30$ at risk of CAN.

Figure 1. Percentage of neuropathy defined by SUDOSCAN in the two populations

(No neuropathy: prediabetics $n=310(69 \%)$, healthy volunteers $\mathrm{n}=350$ (91\%); Neuropathy: prediabetics $\mathrm{n}=117(26 \%)$, healthy volunteers $n=33(9 \%)$; and Severe neuropathy: prediabetics $n=20$ $(5 \%)$, healthy volunteers $n=0(0 \%) ; p$ value comparing the two populations $<0.0001$ ).

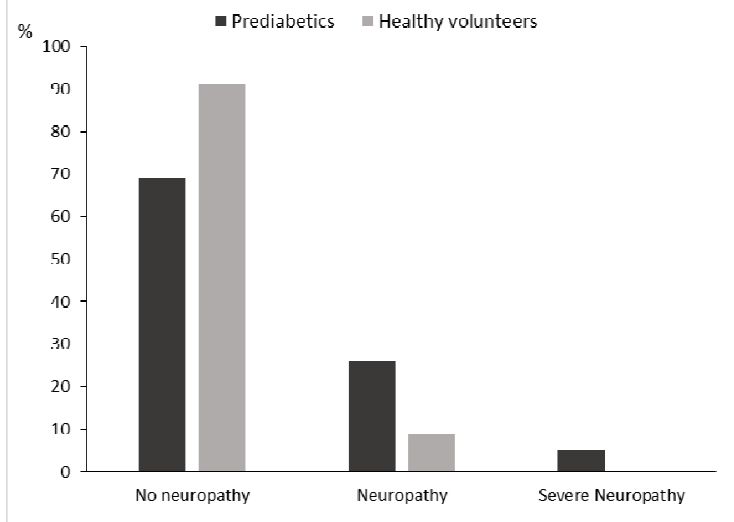

Table 2. Mean values of hands and feet ESC in groups of neuropathy in the two populations

\begin{tabular}{lcccccc}
\hline & \multicolumn{2}{c}{ No neuropathy } & \multicolumn{2}{c}{ Neuropathy } & \multicolumn{2}{c}{ Severe neuropathy } \\
& Prediabetics & $\begin{array}{c}\text { Healthy } \\
\text { Volunteers }\end{array}$ & Prediabetics & $\begin{array}{c}\text { Healthy } \\
\text { Volunteers }\end{array}$ & Prediabetics & $\begin{array}{c}\text { Healthy } \\
\text { Volunteers }\end{array}$ \\
\cline { 2 - 7 } Hands ESC $(\mu S)$ & $75.7 \pm 7.7$ & $74.2 \pm 6.8$ & $56.0 \pm 9.5$ & $57.8 \pm 4.5$ & $37.1 \pm 10.9$ & - \\
Feet ESC $(\mu S)$ & $83.0 \pm 5.1$ & $83.8 \pm 4.9$ & $73.3 \pm 10.3$ & $78.2 \pm 6.1$ & $65.6 \pm 16.6$ & - \\
\hline
\end{tabular}

Among patients with prediabetes percentage of neuropathy in groups of $2 \mathrm{~h}$ OGTT $(<7.8 \mathrm{mmol} / \mathrm{l}$ : no neuropathy $69 \%$, neuropathy $26 \%$, severe neuropathy $5 \% ; 7.8-11 \mathrm{mmol} / \mathrm{l}$ : no neuropathy $72 \%$, neuropathy $24 \%$, severe neuropathy $4 \%$; $\geq 11$ mol/l: no neuropathy $35 \%$, neuropathy $59 \%$, severe neuropathy $6 \%$ ).

\section{DISCUSSION}

Overall prevalence of peripheral neuropathy is very high (31\%) in the prediabetic population as compared to healthy volunteers (9\%). SUDOSCAN is a simple, rapid, and highly reproducible test for use as a screening tool, and as an endpoint in clinical trials on neuropathy in prediabetes. 